\title{
Low Cost Health Monitoring Sytem Based on Internet Of Things Using Email Notification
}

\author{
I Dewa Gede Hari wisana ${ }^{1}$, Bedjo Utomo ${ }^{1}$, Farid Amrinsani ${ }^{1}$, Era Purwanto ${ }^{2}$ \\ ${ }^{1}$ Department of Electromedical Engineering, Poltekkes Kemenkes Surabaya \\ Jl. Pucang Jajar Timur No. 10, Surabaya, 60245, Indonesia \\ ${ }^{2}$ Politeknik Elektronika Negeri Surabaya, Jl. Raya ITS, Keputih, Surabaya
}

\section{Article Information Article History: \\ Received: April 5, 2021 \\ Revision: April 15,2021 \\ Accepted: May 10, 2021}

\section{Keyword:}

Respiration

Sensor Piezoelectric

ESP32

ThingSpeak

\author{
Corresponding author: \\ hariwisana@yahoo.com \\ Departemen of Electromedical Engineering \\ Poltekkes Kemenkes, Surabaya, Jawa Timur, Indonesia
}

\begin{abstract}
Abstrak
Monitoring activities are needed if there are symptoms of a disease that require quick action so that the patient's condition does not get worse, for that we need a system that can notify doctors so they can take action. The patient monitoring system in hospitals is generally still carried out conventionally, among others, nurses or doctors come to the patient's room to check on the progress of the patient's condition, this will be a problem, if the number of medical personnel and facilities is insufficient to monitor. Patients who need special attention for patient care, such as monitoring the patient's breathing rate. The use of the internet of things (IOT), as a device that can work without the help of people, can perform tasks and provide easier and real time data, so that they can access output directly. The purpose of this research is to design an inexpensive health monitoring tool based on the Internet of Things (Respiration Parameters) using a piezoelectric sensor and an ESP32 Wi-Fi module. From the results of the module design taken from 10 respondents, obtained that the average measurement high accuracy $(17.76+0.61)$ and the average level of stability of the design has a magnitude of 0.4 so that it can be concluded that using a piezoelectric sensor in this series can obtain good accuracy. This the design can be used to monitor a person's respiration in real-time.
\end{abstract}

This work is an open access article and licensed under a Creative Commons Attribution-ShareAlike 4.0 International License (CC BY-SA 4.0).

\section{INTRODUCTION}

Monitoring is an activity that is carried out continuously, especially in hospital patients who have certain symptomatic symptoms that require rapid action so that the patient's condition does not worsen, therefore a system is needed that can notify the doctor in order to take action if the patient shows less or more results than normal [1]. Patient monitoring system in hospitals is generally still done conventionally, among others nurses or doctors come to the patient's room to check the development of the patient's condition, this will be a problem, if the number of personnel and medical facilities are limited let alone there are some patients who need special attention such as inpatients [2]. And also in a room with minimal equipment facilities that can pose a risk of monitoring the patient's condition [3]. Handling using manual methods to determine the level of accuracy through physical assessment is intermittent and has been shown to be unreliable [4]. One of the most basic vital signs for monitoring body functions is body temperature, pulse rate, breathing rate, and blood pressure [5]. monitoring of respiratory rates plays an important role in assessing various diseases [6]. Through detection of breathing rate it is easier for the doctor to identify problems from a person's medical history [7]. The indicator used for respiratory examination is calculated within 1 minute or 60 seconds [8]. ]. At the average breathing rate reported in healthy adults at rest is usually administered as 12 breaths per minute $(12 \cdot 60 \mathrm{~Hz})$ but estimates vary between sources for example, 12-20 breaths per minute, 10-14, between 16-18, etc [9]. RR that leads to bradypnea $(R R<12)$ or even apnea (respiratory cessation for an indence period) [10]. There are two kinds of breathing mechanisms, namely chest breathing and abdominal breathing [11]. from observation of respiration signals obtained from the chest and abdominal cavities are quite smooth and the signal strength obtained from sensors in the abdomen is higher compared to sensors in the chest cavity. Mainly due to the larger volume of abdominal expansion compared to the thorax expansion volume [12]. The average accuracy of the tool is $96.09 \%$ and it is concluded that the respiration rate counter tool using piezoelectric sensor has a good accuracy level [13]. Today, there are more than 860 million people with chronic diseases. It is estimated that $25 \%$ of these patients could immediately benefit from a solution to monitor one's health from home, and another 50\% would benefit from the integration of medical resources contained in a mobile phone or other device[14] one of them is the Internet of Things (IoT) device, which is a device that can work without the help of people, to perform tasks and provide easier and accurate data, give them instructions or access the output [15]. 


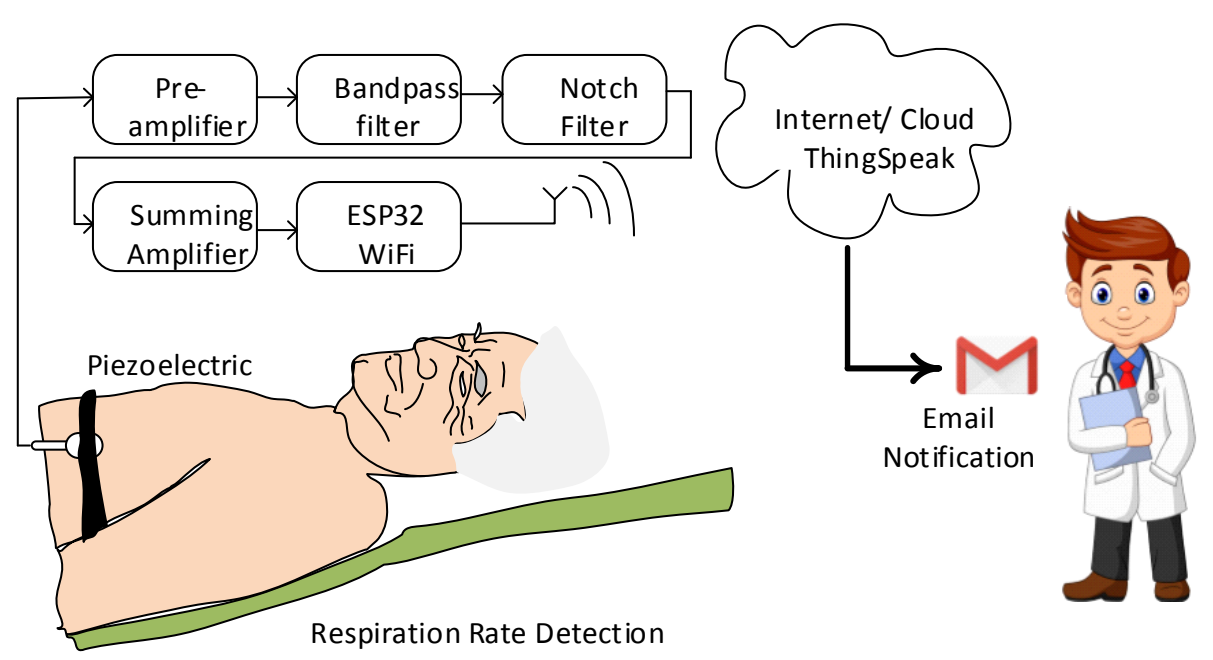

Fig.2 Block Respiration Parameter Diagram

The Internet of things (IoT) is basically some application that includes hardware and software [16]. In this case the internet of things (IoT) has promised the ability to provide efficient data exchange by connecting physical devices and vehicles through electronic sensors and the internett [17]. ThingSpeak is a webbased internet of things (IoT) open information platform conspiring to output sensing data in the form of graphs at the web level. ThingSpeak communicates with the help of a connected internet connection and ThingSpeak retrieves, analyzes, observes and works on data from sensors connected to the microcontroller [17].

Several studies have been conducted, including the development of Respiratory Rate with the title Development Of A Respiration Rate Meter-A Low-Cost Design Approach. This study used IR-LED transmitter and IR-LED receiver. The advantage of this research is the need for a small cost in the manufacturing process and can be used at home. However, this study is still very simple by using a 7 segment view [6]. Then also other research on heart rate monitoring, repiration rate equipped with temperature sensors to personal computers using bluetooth with the advantage of the study is the transmission of data to wireless computers using bluetooth, but this research is still limited by bluetooth distance [18]. Furthermore, Rizal A. P.'s research on BPM monitoring, temperature, and respiration of personal computer appearance via bluetooth and data transmission via SMS, has the advantage of being notified via SMS, while the shortcomings of the study are the lack of accurate sensors used. This condition will result in a mismatch of measurements [19]. Another researcher titled Design of LCD Graph Appearance Respiratory Equipment with Patient Data Storage. It has the advantage that there is storage of the patient's examination results on the SD card. While the disadvantage of this study is that it still uses lcd display graphics [20]. While in the study on "Non-Invasive Spirometer with Piezoelectric Sensors for Lung Health Detection". The advantage is that there is data storage on the SD card, for that we will expand IoT- based research that can answer technological challenges in the future at a low cost. [21]

The purpose of this study was to design an Internet Of Things Based Health Monitoring Tool using piezoelectric sensors. The use of these sensors has been widely used for various quality assurance and control processes developed in various industries because it has high natural frequencies and excellent linearity in a wide amplitude range[22]. By utilizing IoT (Internet of Things) based technology, the display of values and graphs of each parameter can be continuously known in realtime.

\section{MATERIAL AND METHODS}

\section{A. Experimental Design}

This study was conducted using OEM ceramic piezoelectric sensors attached to the abdomen of respondents. The patient should be in a relaxed state. Retreival data in adult respondents with the age category $17-45$ years and each respondent was done 10 times the measurement.

\section{1) Tools and Materials}

This study used ceramic piezoelectric sensors (Polyvinylidene Fluoride, OEM, LA20190517001jl, China) to detect respiration placed on the abdomen as shown in figure 2. Of components used such as summing amplifier circuits to amplify respiration signals, a series of low pass filters for noise removal, and the ESP-WROOM-32 module (211-161007, Espressive Systems Wi-fi module, Shanghai China) as a connection with the internet to display results on the ThingSpeak web, and for the display of its respiration values using Android (Version 1.8.10).

\section{2) Experiments}

The trial is conducted after the module is complete. respiration circuit output measurements are performed using a digital oscilloscope. In this study, data retrieval did to adult 
respondent with lifespan 17-45 years and the responden with data retrieval as many as 10 times.

\section{B. Block Diagrams}

Figure 1 ceramic piezoelectric sensor used to detect respiration

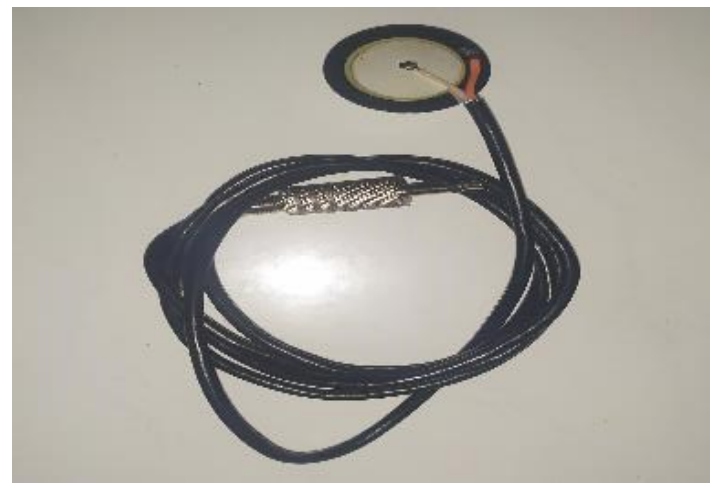

Gambar 1 Sensor Piezoelektrik Keramik

In Figure 2 the parameter chart blocks of the piezoelectric sensor will be processed on a series of summing amplifiers and low pass filters. The output of the analog signal conditioning will be managed by a microcontroller with esp32 wi-fi module the data will be displayed on the ThingSpeak web and equipped with a notification on gmail, if there is an indication of abnormal results on the respiration.

\section{A. Flowchart}

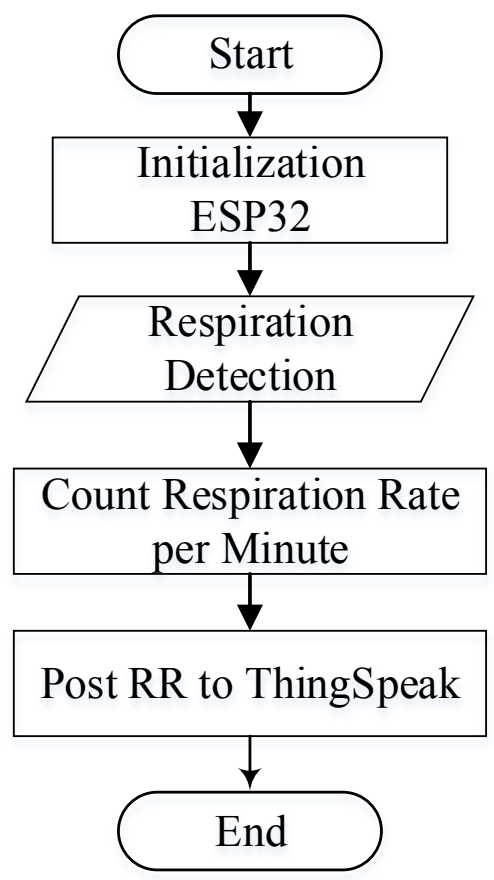

Gambar 3 Diagaram Alir Transmitter
In the flow chart Figure 3 starts at the start there will be an initialization process. The sensor of each parameter will work. OEM ceramic piezoelectric sensors will work to detect respiration and the microcontroller will process the data and then perform the calculation of the respiration value. The data results will be sent to the ESP32 wi-fi module and then displayed on the ThingSpeak web. If the respiration $<12$ or respiration $>20$ value, it automatically sends a respiration value notification via Gmail as described in figure 4.

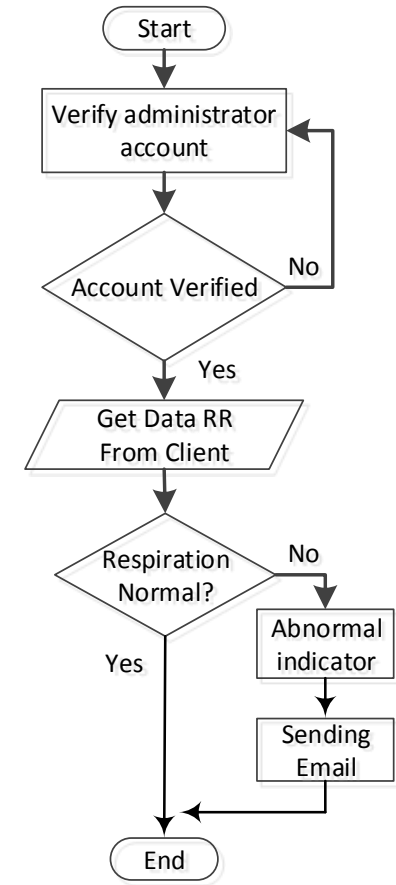

Fig. 4. The receiver flowchart

D. Analog Circuit

An important part of this module is the analog circuit consisting of a series of summing amplifiers and a low pass filter. This circuit is used to process respiration signals that have been read by piezoelectric sensors.

1) Circuit Summing Amplifier

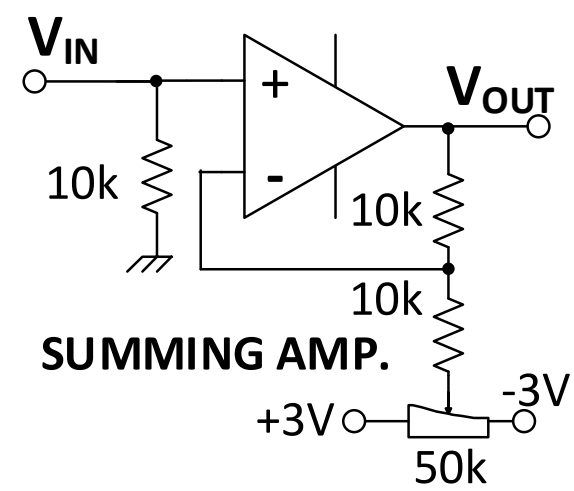

Gambar 5 Circuit Summing Amplifier 
The summing circuit of the amplifier is shown in Figure 5. This circuit serves to condition the output of the piezoelectric sensor signal, the signal produced from the piezoelectric sensor is still small so it needs to be strengthened using a series of summing amplifiers.

\section{2) Circuit Low Pass Filter}

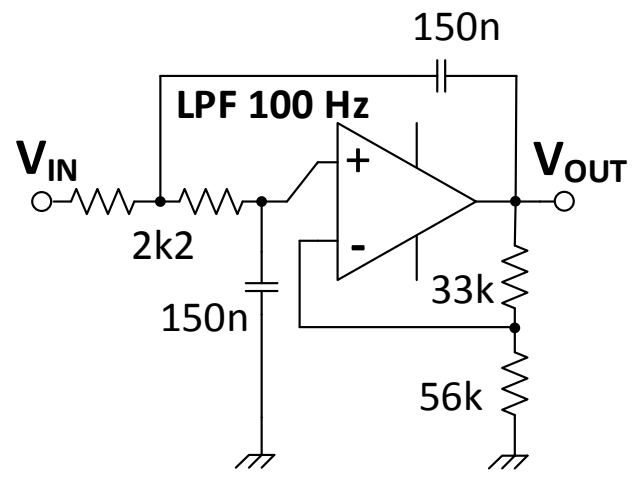

Gambar 6 Circuit Low Pass Filter

The series of low pass filters shown in Figure 6 serves to pass frequencies below the output frequency and is used to eliminate noise contained in the reinforcement circuit. In designing the low pass filter circuit, the author designed the active filter set. The set of low pass filters created has a cut off frequency of $1 \mathrm{~Hz}$. The respiration circuit output is connected on the D35 pin, the respiration indicator LED is connected on pin D12, the Vin pin and ground are connected to the tool supply. Furthermore, to process the data of each parameter and also used for sending the results of the data using the web ThingSpeak

\section{RESULTS}

In this study the utilization of low-cost internet-based health monitoring used ceramic piezoelectric sensor sensors to detect respiration made simple and the manufacture of ESPWROOM-32 module for data transmission as shown in the design of figure 7 below

A. The design

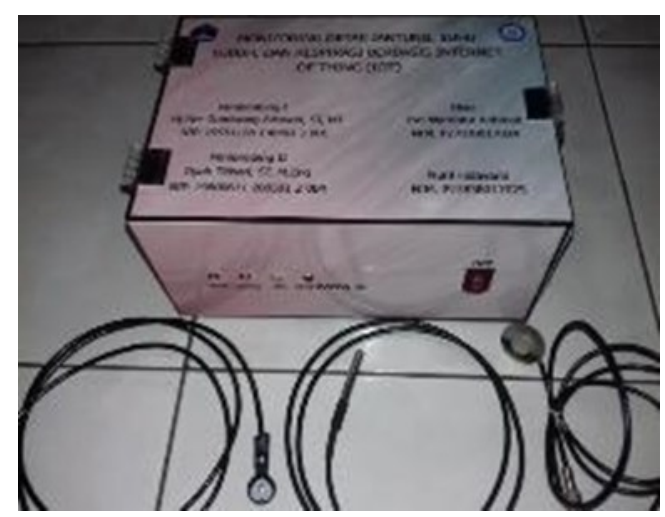

Fig. 7 Tool Design Results
In fig. 7 shows the design results of the tool. On the front of the appliance is a piezoelectric sensor mounting station and a respiration indicator led that lights up during breathing. the range consists of OEM ceramic piezoelectric sensors to detect the number of breaths per minute as well as a PSA (Analog Signal Conditioning) circuit consisting of a series of summing amplifiers and low pass filters to condition the output of the sensor. Measurement data was performed on respondents as many as 10 times the data capture shown in fig. 8 below

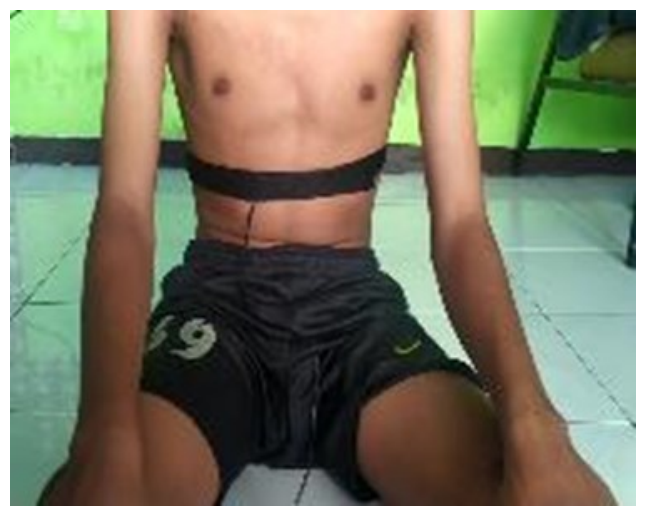

Fig. 8. Respiration Measurement Process in Respondents

\section{B. Listing Program for ESP32 Wi-Fi}

Esp32 wi-fi module program listing consists of processing program and respiration value calculation shown in program listing program 1, ThingSpeak web initialization program on program listing 2, and delivery program on ThingSpeak web shown in program listing 3 .

Listing Program 1. Respiration Value Readings

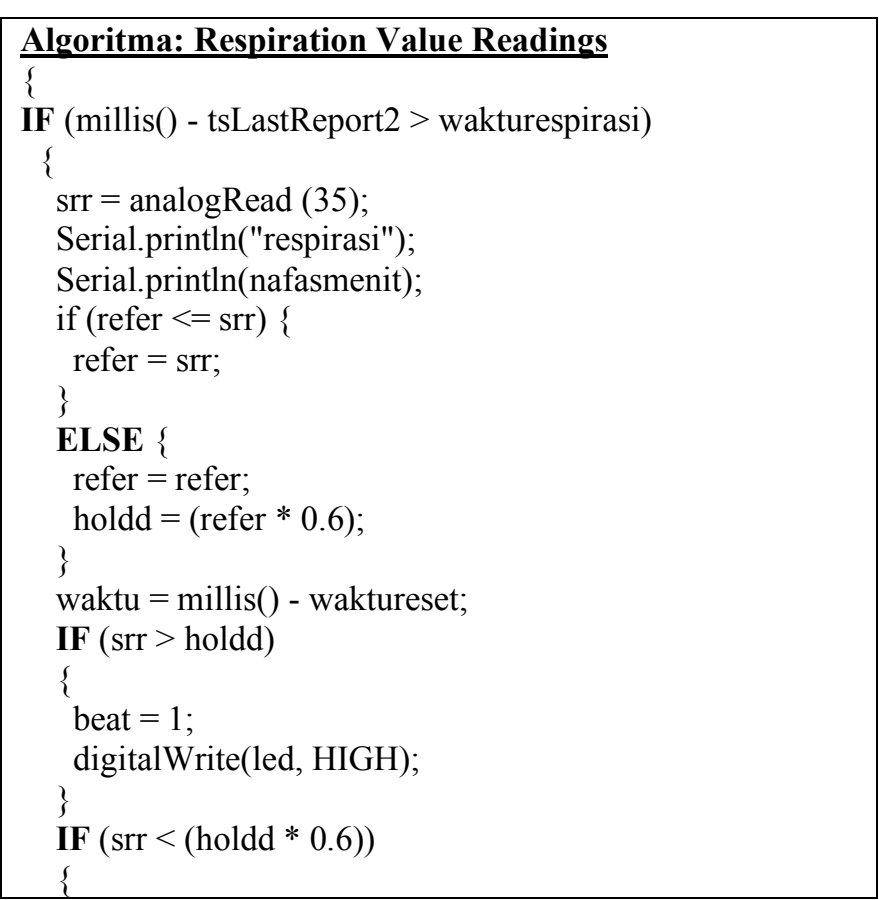




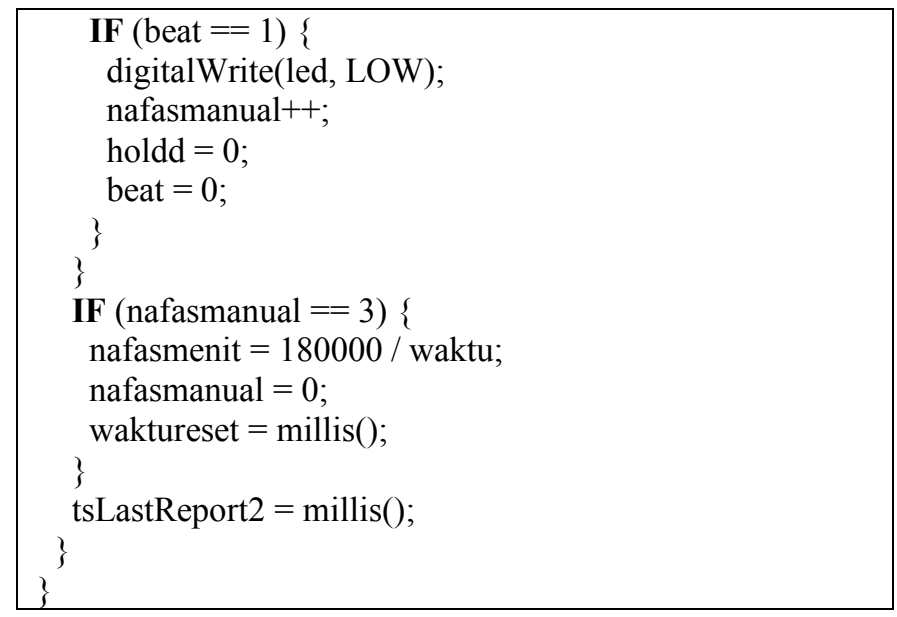

When the input signal is greater than the autoreference, it automatically performs a read then automatically calculates the respiration value and sends the result to ThingSpeak. The respiration value reading is indicated on the program listing 1.

Listing Program 2. ThingSpeak Initialization Program

Algoritme: Program Initialization ThingSpeaks
const char ssid[] = "Redmi"; // your network SSID (name)
const char password[] = "evas051098"; // your network
password
keyIndex int = 0; // your network key index number (needed
only for WEP)
const long CHANNEL = 899428;
const char *WRITE API = "1CORJY6EXGF7COS4";

Before making a delivery to ThingSpeak first do the wifi connection settings. Must fill in the name of the wifi connection and the password connected. In addition to setting the wifi connection must also fill in the channel number and write the APIKEY listed on the thingspeak account that has been registered to connect with the channel to be accessed.

Listing Program 3. Delivery Program on ThingSpeak

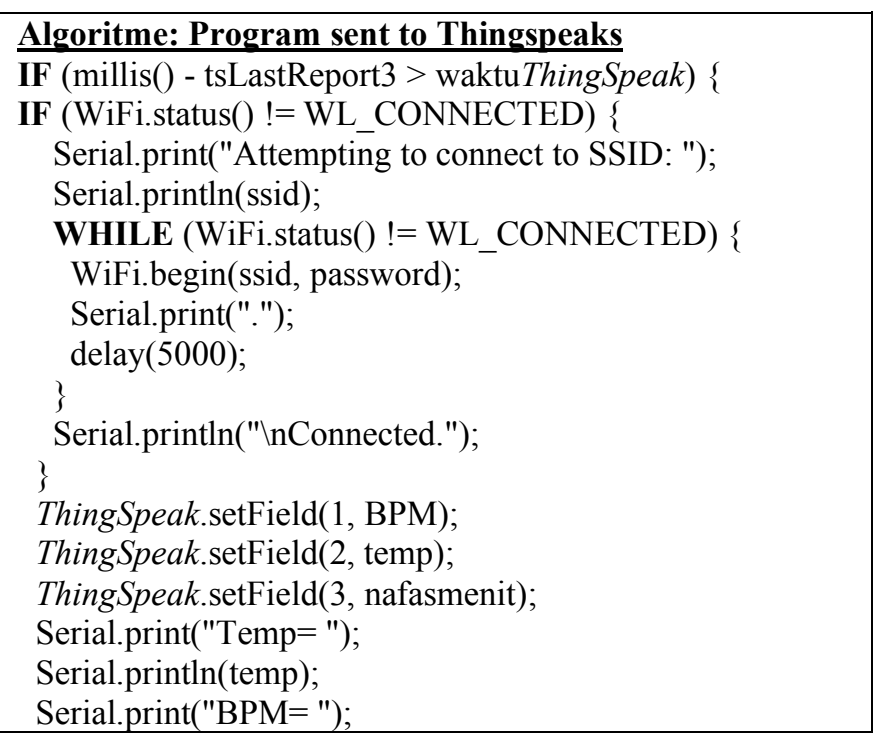

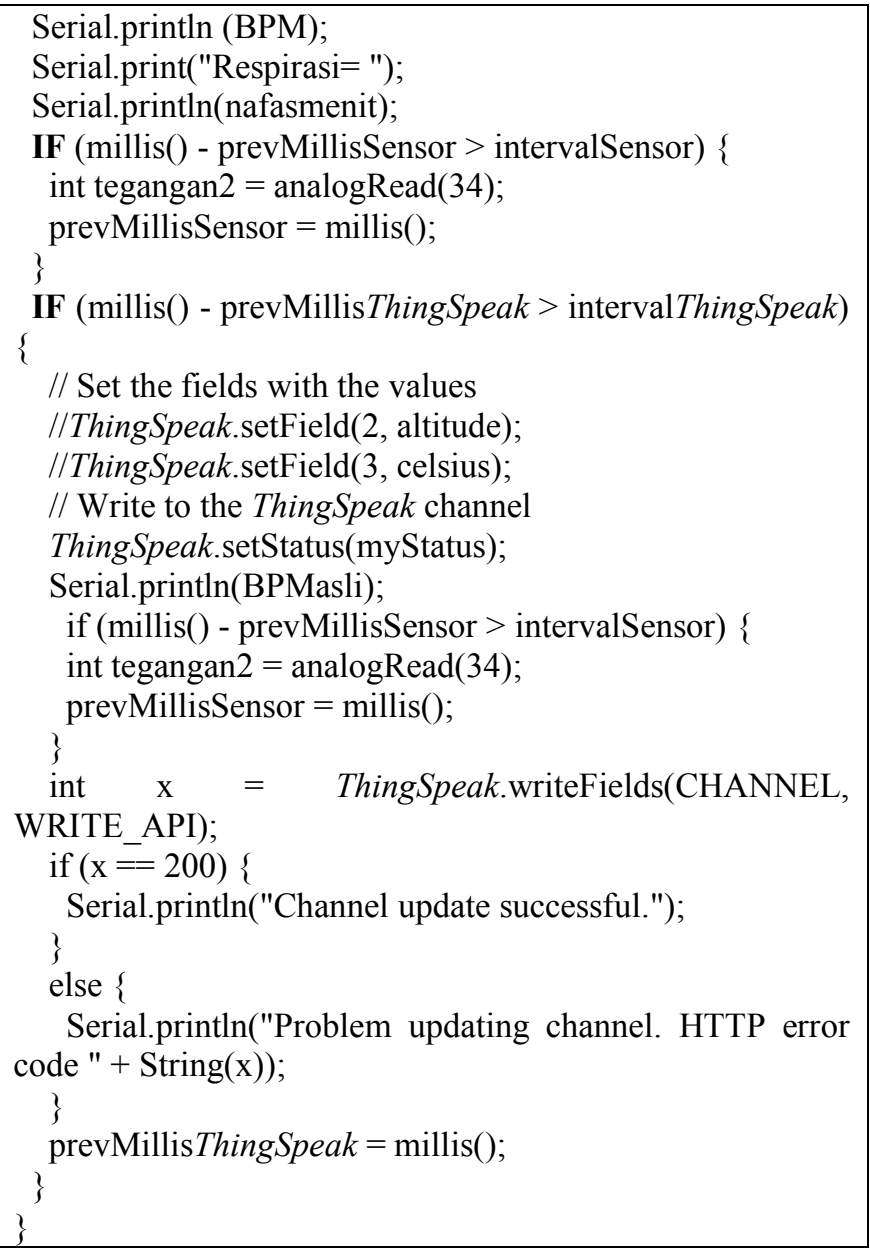

After the initialization on ThingSpeak has been done then the ESP32 module will connect to the network that has been initialized in the program, if it is not connected it will send text/string data "." If it is already connected then the display on the serial monitor is "Connected". It will then send the 'Respiration' data in field 3, if the delivery is successful it will display "Channel update successful." on the monitor series.

\section{B. Respiration Circuit Output Signal Results in Arduino} Serial Plotters

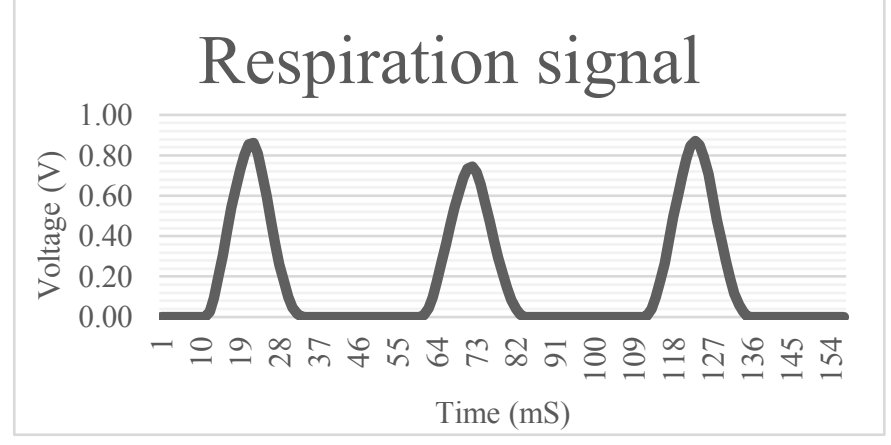

Fiq. 12. Signal Results When There Are Patients

\section{Accredited by Ministry of Research and Technology /National Research and Innovation Agency, Indonesia Decree No: 200/M/KPT/2020}


Fig. 12 is the result of a signal on the output of the respiration circuit when there is a patient. The respiration circuit output is a signal that has passed through a series of summing amplifiers and low pass filters. The resulting signal has an amplitude exceeding the reference limit then get logic 1 (one) so that the signal reads that a breathing process occurs.



Fiq. 13. Signal Results When There no Patients

Fig. 13 is the result of a signal on the output of the respiration circuit when there is no patient. The result of the signal has a very small amplitude so it gets a logic of 0 (zero) so that the signal is unreadable.

D. Respondents' Respiration Measurement Results

TABLE I. RESPONDENT RESPIRATION MEASUREMENT RESULTS

\begin{tabular}{ccc}
\hline Subjects & $\begin{array}{c}\text { Mean } \\
\text { (Breaths per } \\
\text { minute) }\end{array}$ & Standar Deviasi \\
\hline 1 & 19,3 & 0,533 \\
2 & 20,3 & 0,578 \\
3 & 19 & 0 \\
4 & 16,3 & 0,578 \\
5 & 17,7 & 0,578 \\
6 & 19 & 1,732 \\
7 & 15 & 0 \\
8 & 18 & 0 \\
9 & 18,7 & 1,528 \\
10 & 14,3 & 0,578 \\
\hline
\end{tabular}

In Table I shows the average and standard deviation of respiration measurement obtained after the measurement of 10 respondents, and in each respondent was measured 3 times.

E. Tool Stability Test Results
TABLE II. DESIGH STABILITY TEST RESULTS

\begin{tabular}{ccc}
\hline Value & $\begin{array}{c}\text { Value } \\
\text { Respiration } \\
\text { (Breaths per } \\
\text { minute) }\end{array}$ & $\begin{array}{c}\text { Difference in } \\
\text { Respiration Value } \\
\text { and Average } \\
\text { Respiration Value }\end{array}$ \\
\hline 0 & 0 & 0 \\
1 & 14 & $|1|$ \\
2 & 15 & 0 \\
3 & 15 & 0 \\
4 & 16 & 1 \\
5 & 15 & 0 \\
6 & 15 & 0 \\
7 & 16 & 0 \\
8 & 15 & $|1|$ \\
9 & 14 & 0 \\
10 & 15 & Total $=4$ \\
Average & & \\
Value & 15 & \\
Respiration & & \\
\hline
\end{tabular}

Table II shows the results of the tool stability test. Measurement has been done on 1 respondent, by taking measurements as many as 10 times. From the results of the measurement obtained the average respiration value is 15 . Furthermore, from the average difference value of the respiration value obtained an average error value of 0.4 for the respiration parameter.

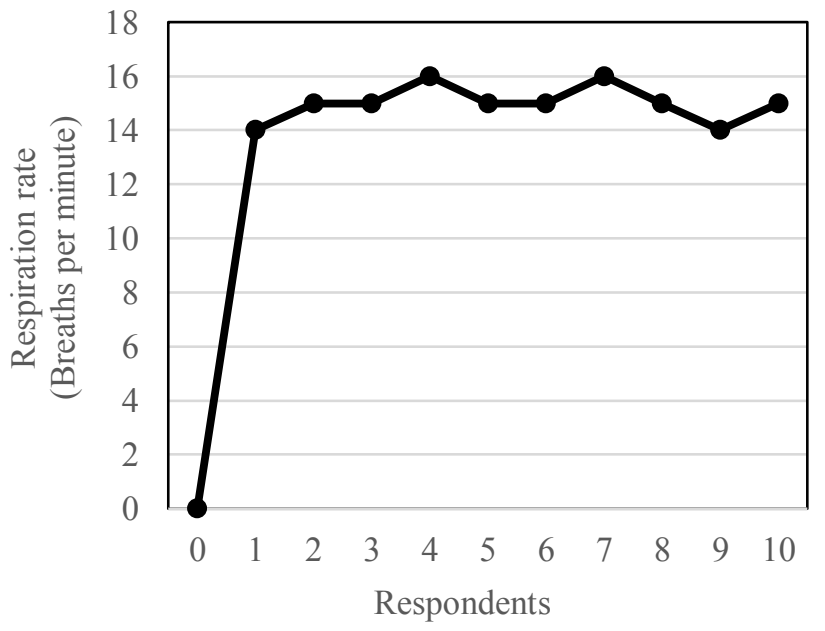

Fiq. 14. Tool Stability Testing Graph

Fig. 14 shows a graph of the tool's stability results on the respiration parameters shown by the measurement of 1 respondent with 10 data captures. With an average error the tool is worth 0.4 . 


\section{F. Measurement of Delivery Delay on ThingSpeak}

The value of the module measurement result will be displayed on ThingSpeak with the same value as the module submitted, only that there is a delay between the results displayed on the account and those displayed on the module that should be \pm 15 seconds turns out that the realization result has an average delay of 18 seconds. If there are problems at the time of the update this is a factor of the unstable internet network.

\section{DISCUSSION}

From the results of the tool stability test shown in Table II there is an average error of 0.4 . This proves that it has good stability. By using piezoelectric sensor the respiration rate has an average of $17.76+0.61$ meaning a good accuracy range[13]. To get the right test results, the respondent must be calm and relaxed because it will affect the results of the examination. In previous studies, fc-04 sensors were still not accurate, resulting in a discrepancy in measurements[13]. In previous studies, fc-04 sensors were still not accurate, resulting in a discrepancy in measurements [19]. The tool that has been made is an improvement of the respiration value data transmission system that previously still uses Bluetooth so that it can not be done remote monitoring or still limited by Bluetooth distance [18]. The measurement results that appear in the ThingSpeak view match the values generated by the tool. It's just that there is a delay between the results that appear on the account and those that appear in the module that should be \pm 15 seconds turns out that the realization results have an average delay of 18 seconds. However, the measurement results from respondents are fickle due to several factors, namely, the placement of piezoelectric sensors, respondents who do not relax resulting in interference in the respiration signal, and the results that appear on the Web ThingSpeak relies heavily on the internet network that is not always stable delivery capability.

\section{CONCLUSION}

The purpose of this study is to design a low-cost design to monitor the respiration rate using internet of thing technology and to send a notification for the doctor or family. The results showed that the average value of measurements with high accuracy $(17.76+0.61)$ and the average level of stability of the design has a magnitude of 0.4 thus the design can be used to monitor a person's respiration in real-time. For future research is expected to be made monitoring applications with faster data delivery.

\section{REFERENSI}

[1] I. Prayogo et al., "Sistem Monitoring Denyut Jantung Dan Suhu Tubuh Sebagai Indikator Level Kesehatan Pasien Berbasis IoT ( Internet Of Thing ) Dengan Metode Fuzzy Logic Menggunakan Android," Triacs, vol. 2, pp. 1-8, 2017.

[2] M. A. Mega and M. R. Firdaus, "Monitoring Detak
Jantung , Suhu, dan Infus pada Pasien Berbasis Mikrokontroler ( ARDUINO MEGA2560 ) Monitoring Heartbeats , temperature and Infusion in Patients Based," Telekontran 1 , vol. 5, no. 1, pp. 55-64, 2017.

[3] W. Wen Qi Mok and S. Y. L. Wang, "Vital signs monitoring to detect patient deterioration: An integrative literature review," Int. J. of Nursing Pract., vol. 2, no. 21, pp. 91-98, 2015.

[4] I. Mahbub, H. Wang, and S. K. Islam, "A Low Power Wireless Breathing Monitoring System Using Piezoelectric Transducer," Dep. Electr. Eng. Comput. Sci. Univ. Tennessee, Knoxville, TN 37996, USA, no. June 2018, 2016.

[5] L. W. S. H. Bertil Hok, "A new respiratory rate monitor: development and initial clinical experience," Int. J. Clin. Monit. Comput., vol. 10, pp. 101-107, 1993.

[6] S. Das, "Development Of a Respiration Rate Meter - A Low - Cost Design Approach,” Int. J., vol. 2, no. 2, 2013.

[7] M. C. J. Christ and S. G. A. Lenin, "Design of a PC-Based Respiration Rate and Temperature Recorder as Internet Appliance," Int. J. Sci. Res. Dev., vol. 3, no. 01, pp. 667669, 2015.

[8] A.Potter Patricia, "Fundamental Of Nursing," in 7th, 2009.

[9] A. Anand, A. R. K, K. Greeshma, K. Jaseena, and R. Rahul, "Design of Digital Respiration Rate Meter," Int. J. Comput. Appl., vol. 118, no. 14, pp. 28-30, 2015.

[10] R. G. Manjunatha, N. Ranjith, Y. V Meghashree, K. Rajanna, and D. R. Mahapatra, "Identification Of Different Respiratory Rate By A Piezo Polymer Based Nasal Sensor," Dep. Instrum. Appl. Phys. Indian Inst. Sci., pp. 1-4, 2013.

[11] E. Purjiyanta, Mekanisme Pernapasan dada dan Perut Artikelsiana. Jakarta: Erlangga, 2006.

[12] S. Talha, A. Hadmani, A. Fernando, and P. Potluri, "The application of a piezo-resistive cardiorespiratory sensor system in an automobile safety belt," Int. Electron. Conf. Sensors Appl., pp. 1-6, 2014.

[13] Ari Wibowo Setiyo. Rizal Achmad. Hidayat Iswahyudi, "Realization of Piezoelectric Sensor for Measuring Respiration Rate Based on PC," Fak. Elektro dan Komun. - Inst. Teknol. Telkom, pp. 1-9.

[14] A. M. C. D. C. and R. Morello, "A remote doctor for homecare and medical diagnoses on cardiac patients by an adaptive ECG analysis," 2009 IEEE Int. Work. Med. Meas. Appl., pp. 31-36, 2009.

[15] M. Prasanna, M. Iyapparaja, M. Vinothkumar, B. Ramamurthy, and S. S. Manivannan, "An Intelligent Weather Monitoring System using Internet of Things," Int. J. Recent Technol. Eng., no. 4, pp. 4531-4536, 2019.

[16] P. Bhadane and A. Lal, "Beginners Approach to the Open Source Programming : Case Study Arduino with ESP32," 
Int. J. Comput. Sci. Eng., no. 10, pp. 445-448, 2018.

[17] S. Pasha, "Thingspeak Based Sensing and Monitoring System for IoT with Matlab Analysis," Int. J. New Technol. Res., vol. 2, no. 6, pp. 19-23, 2016.

[18] R. D. A. Ikrar, I. G. D. H. W, and T. Hamzah, "Monitoring Heart Rate , Respiration Rate di lengkapi Sensor Suhu ke Personal Komputer menggunakan Bluetooth," $J$. Teknokes, 2016.

[19] R. A. Prayugo, "Monitoring BPM, Suhu dan Respirasi Tampil PC via Bluetooth dan Pengiriman Data via SMS (Monitoring Suhu dan Respirasi Tampil PC via Bluetooth)," Jur. Tek. Elektromedik Politek. Kesehat. Surabaya, 2018.

[20] T. H. A. Key, T. Sch, J. E. Tech, "Design of LCD Graph Appearance Respiratory Equipment with Patient Data Storage," Sch. J. Eng. Technol. ( SJET), pp. 282-287.

[21] P. S. Wardana and R. Adil, "Spirometer Non-Invasive dengan Sensor Piezoelektrik untuk Deteksi Kesehatan," J. ELKOMIKA, vol. 5, no. 2, pp. 188-206, 2017.

[22] N. Shankar and K. Sankar, "Measurement of Respiratory Rate Using Peizoelectric sensor," Int. J. Sci. Res. Rev., vol. 7, no. 1, pp. 184-188, 2018. 